\title{
Bilateral peroneal artery aneurysms
}

\author{
O El Bakbachi ${ }^{1}$, GA Antoniou ${ }^{2}$, RG McWilliams ${ }^{1}$, DR Jones ${ }^{1}$ \\ ${ }^{1}$ Vascular and Endovascular Service, Royal Liverpool University Hospital, Liverpool, UK \\ ${ }^{2}$ Department of Vascular and Endovascular Surgery, The Royal Oldham Hospital, Pennine Acute \\ Hospitals NHS Trust, Manchester, UK
}

\section{ABSTRACT}

True aneurysm of the tibial arteries is a rare clinical condition. We report the case of a 67 -year-old man who presented with a gradual onset of right calf swelling and pain. Imaging revealed large aneurysms arising from the proximal peroneal arteries bilaterally, measuring $7.4 \mathrm{~cm}$ and $4 \mathrm{~cm}$ on the right and left respectively. A detailed medical history, clinical examination and laboratory investigations did not identify evidence of an underlying cause. A surgical reconstruction with an interposition vein graft was successfully performed. To our knowledge, this is the first reported case of primary aneurysm of the peroneal artery in the English literature. We undertook a systematic literature review to identify all reported cases of primary aneurysms of the tibial arteries. The clinical presentation, modes of investigation and interventional treatments are discussed.

\section{KEYWORDS}

Aneurysm - Peroneal artery - True

Accepted 3 January 2017

CORRESPONDENCE TO

George A Antoniou, E: antoniou.ga@hotmail.com

True aneurysm of the tibial arteries is a rare clinical condition. ${ }^{1}$ The pathogenic mechanisms are largely unknown but they have been linked to an inflammatory process. ${ }^{2}$ More commonly reported aetiologies of aneurysms arising from the crural arteries include arterial trauma and infection, resulting in pseudoaneurysm formation. ${ }^{2}$

To our knowledge, a true aneurysm of the peroneal artery has not been reported previously. We describe a case of primary bilateral peroneal artery aneurysms treated successfully with surgical reconstruction. A systematic review of the literature was carried out to identify all reported cases of true aneurysms of the tibial arteries. Baseline demographics, clinical characteristics, methods of treatment and outcomes are compared.

\section{Case history}

A 67-year-old man was referred to our tertiary vascular centre with an 8-week history of right calf pain and swelling. He denied claudication symptoms affecting his legs. His past medical history was significant for ischaemic heart disease (treated previously with a coronary artery bypass and percutaneous coronary intervention) and hypertension. He never smoked, and was otherwise fit and well. Clinical examination identified a non-pulsatile swelling on the posteromedial aspect of the calf with a smooth and normal overlying skin. A full complement of femoral and infrainguinal pulses was present bilaterally.
Duplex ultrasonography showed a $7.4 \mathrm{~cm}$ aneurysm arising from the peroneal artery. Contrast enhanced computed tomography (CT) confirmed a patent saccular aneurysm at the proximal segment of the right peroneal artery with concentric mural thrombus and a lumen of $3 \mathrm{~cm}$ (Fig 1). The distal peroneal artery remained patent. The posterior tibial artery was of small calibre but patent. CT also revealed a $4 \mathrm{~cm}$ aneurysm in the proximal segment of the contralateral peroneal artery with a fusiform morphology, and normal appearances of the arteries proximal and distal to the aneurysm (Fig 2).

A detailed medical history, clinical examination and laboratory investigations failed to identify evidence of an underlying cause of the aneurysms. Echocardiography was normal, the patient was apyrexial, blood cultures were negative, inflammatory markers were not raised and there was no history of trauma to the legs.

The case was discussed at our multidisciplinary team forum, where surgical and endovascular treatments were considered. A decision was made to treat the aneurysms with a surgical bypass operation. The patient gave informed consent. The aneurysm was accessed through a medial calf incision. The distal popliteal artery was dissected and the anterior tibial vein was ligated to allow mobilisation of the tibioperoneal trunk. The proximal anterior and posterior tibial arteries and the peroneal artery were controlled with vessel loops. Balloon occlusion catheters were used in the peroneal artery proximal and distal to the aneurysm for haemostatic control. The aneurysm was successfully repaired 


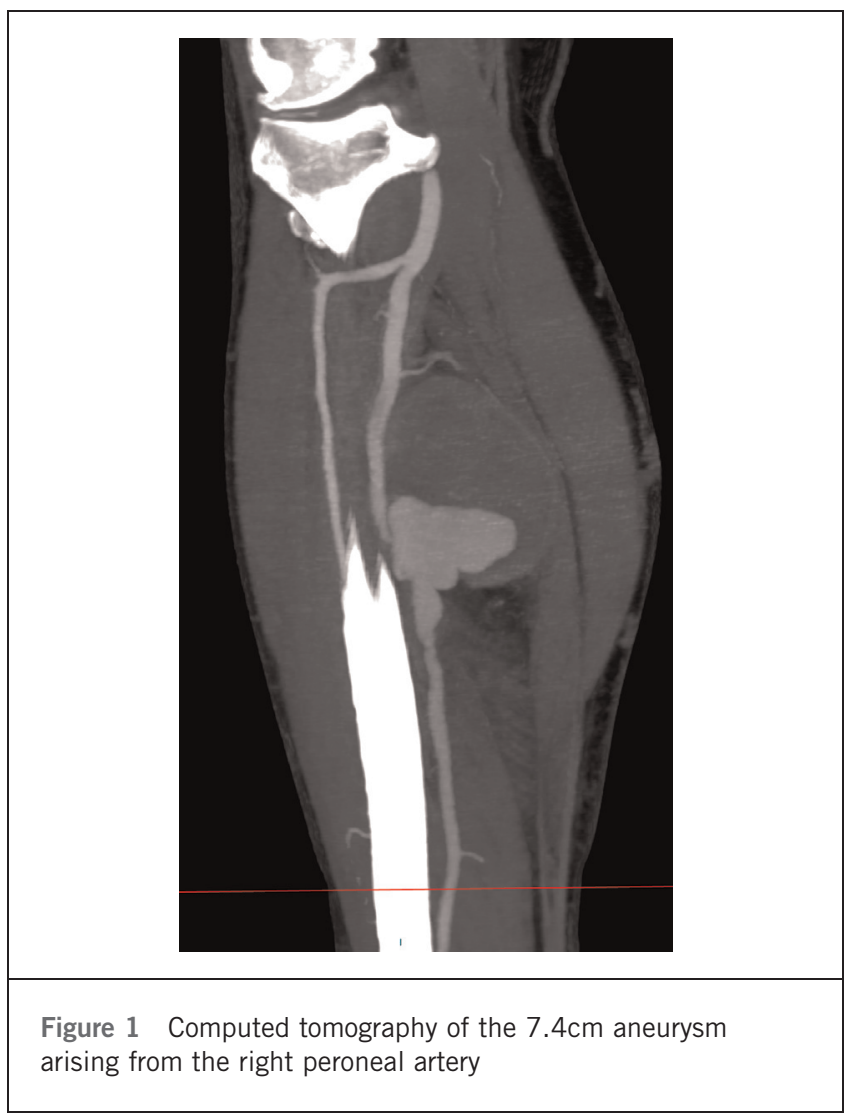

with resection and interposition of a reversed great saphenous vein graft. The tibial nerve was identified and preserved.

The operation was accomplished with no complications. Perfusion of the leg was preserved with a palpable dorsalis pedis and posterior tibial pulse. The patient had an uneventful postoperative course and was discharged on day 4. At the six-week follow-up visit, the patient reported no claudication symptoms. He remained well six months later. Histological analysis demonstrated a partially thrombosed true atherosclerotic aneurysm with no signs of infection, arteritis or connective tissue disorder. Intraoperative thrombus samples were sent for extended microscopy, culture, sensitivity and polymerase chain reaction analysis; no organisms or growth were seen. On this occasion, a vasculitis screen was not requested.

The left side aneurysm was asymptomatic. However, a decision was made to operate in few months' time and contralateral surgery is now planned at a later date.

\section{Discussion}

The popliteal artery is the most frequent site of true peripheral aneurysms. ${ }^{3}$ True aneurysms of the tibial arteries are uncommon. Pseudoaneurysms secondary to infection, trauma or iatrogenic injury have been reported. ${ }^{4}$ Infective endocarditis, as a result of Gram-positive organisms in

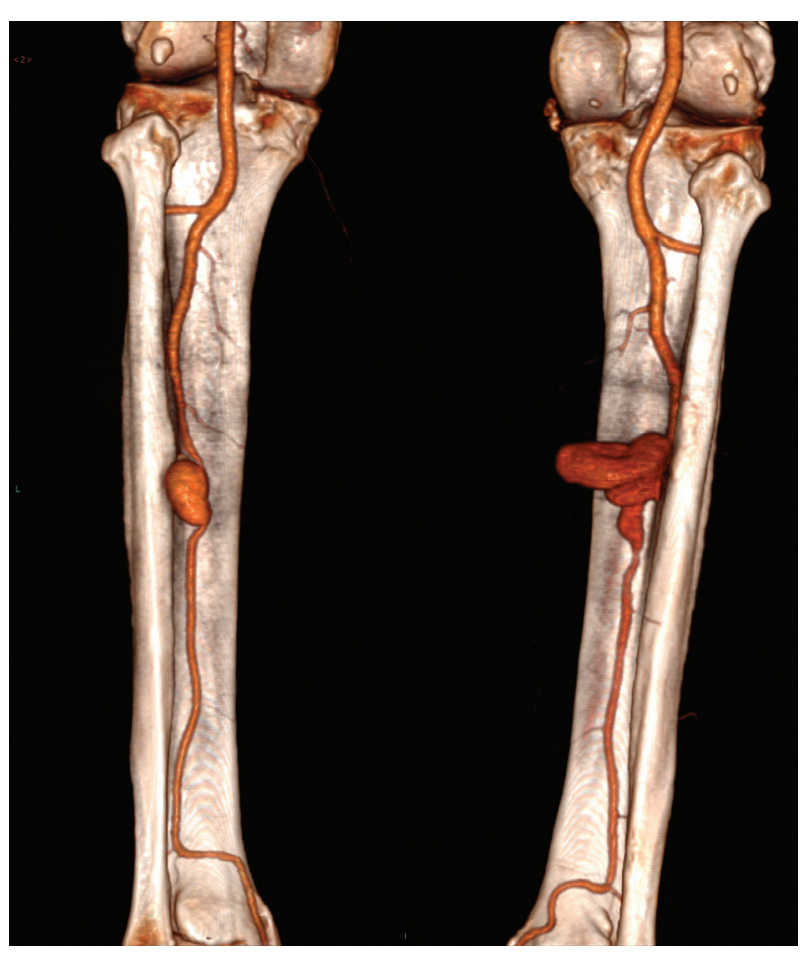

Figure 2 Three-dimensional computed tomography of bilateral peroneal artery aneurysms

intravenous drug abusers, is the main cause of mycotic aneurysms. ${ }^{5}$

To our knowledge, there have been no reported cases of bilateral or single true primary peroneal artery aneurysm. The saccular morphology of the right peroneal artery aneurysm indicates a possible previous rupture of a true aneurysm resulting in a combination of a true and false aneurysm. Five cases of peroneal artery aneurysm of mycotic aetiology have been described in the literature and are summarised below. ${ }^{6-10}$

Ferrero et al reported a 69 -year old man with a sudden onset of pain in the right calf without signs of leg ischaemia. ${ }^{6}$ The diagnosis of a mycotic peroneal artery aneurysm was made based on the unusual location of the aneurysm, clinical presentation and positive blood cultures. The aneurysm was treated with coil embolisation and placement of a covered stent.

Another mycotic aneurysm was described by McKee and Ballard. ${ }^{7}$ They reported a 15 -year-old boy with bilateral peroneal artery aneurysms resulting from Candida endocarditis following a cardiac valve replacement operation. Symptoms and clinical signs included pyrexia, a systolic murmur and a pulsatile mass with a thrill on the medial aspect of the calf. The left peroneal artery aneurysm was treated with an open surgical repair (resection) whereas the right-sided aneurysm was repaired with coil embolisation. 
Albayrak et al reported a mycotic aneurysm of the peroneal artery in a 37-year-old man who presented with weakness, sweating, cough, weight loss and right calf pain. ${ }^{8}$ Blood cultures confirmed the presence of Staphylococcus aureus infection, suggestive of infective endocarditis. Echocardiography also confirmed vegetations on the mitral and aortic valve. Surgical treatment was undertaken with ligation of the peroneal artery proximal and distal to the aneurysm.

A further report described a 61-year-old woman with a history of infective endocarditis secondary to Acinetobacter following tooth extraction. ${ }^{9}$ Soon afterwards, she developed pain and swelling in the left calf, and a mycotic aneurysm of the peroneal artery was identified. Surgical excision of the aneurysm was performed successfully.
Another pseudoaneurysm arising from the peroneal artery was reported in a 72-year-old man with a large firm mass below the right popliteal fossa. ${ }^{10}$ The patient had had a previous episode of septicaemia due to Staphylococcus aureus, after which he developed a painless swelling in the right calf. Treatment consisted of direct human thrombin injection.

Four true aneurysms of the tibioperoneal trunk have been reported (Table 1) ${ }^{11-14}$ In three of these cases, the patients presented with a pulsatile and/or painful mass. ${ }^{11,13,14}$ Other symptoms necessitating urgent investigations have been described, including blue toe syndrome. ${ }^{14} \mathrm{~A}$ high index of suspicion is required for a prompt diagnosis. In one of the reported cases, the aneurysm was initially misdiagnosed as myalgia in the right gastrocnemius muscle because all

Table 1 Summary of literature on true aneurysms of the tibial arteries and tibioperoneal trunk

\begin{tabular}{|c|c|c|c|c|}
\hline & Age / sex & Method of treatment & Outcome & Clinical framework \\
\hline $\begin{array}{l}\text { Cappendijk, } \\
1999^{11}\end{array}$ & $60 \mathrm{~F}$ & $\begin{array}{l}\text { Saphenous vein } \\
\text { bypass }\end{array}$ & $\begin{array}{l}\text { Symptoms resolved. } \\
\text { Graft patent at } \\
15 \text { months following } \\
\text { intervention. }\end{array}$ & $\begin{array}{l}\text { Presentation: Persistent pain and } \\
\text { palpable mass in the right calf. No } \\
\text { history of trauma. } \\
\text { Aetiology/risk factors: Hypertension, } \\
\text { dyslipidaemia } \\
\text { Investigations: DUS, CT arteriography } \\
\text { Diagnosis: Aneurysm of the tibiopero- } \\
\text { neal trunk }\end{array}$ \\
\hline $\begin{array}{l}\text { Spronk, } \\
2003^{12}\end{array}$ & $52 \mathrm{~F}$ & $\begin{array}{l}\text { Excision of the } \\
\text { aneurysm followed } \\
\text { by reconstruction } \\
\text { using a venous } \\
\text { patch }\end{array}$ & $\begin{array}{l}\text { Ischaemic symptoms } \\
\text { disappeared } \\
\text { completely. } \\
\text { Patent neotibioperoneal } \\
\text { trunk. }\end{array}$ & $\begin{array}{l}\text { Presentation: Painful, ischaemic toes of } \\
\text { right foot } \\
\text { Aetiology/risk factors: Smoking } \\
\text { Investigations: DUS, arteriography } \\
\text { Diagnosis: Partially thrombosed aneur- } \\
\text { ysm measuring } 2.5 \mathrm{~cm} \text { at the origin of } \\
\text { the right tibioperoneal trunk }\end{array}$ \\
\hline $\begin{array}{l}\text { Ferrero, } \\
2011^{13}\end{array}$ & $66 \mathrm{~F}$ & $\begin{array}{l}\text { Aneurysmectomy } \\
\text { with end-to-end } \\
\text { anastomosis }\end{array}$ & $\begin{array}{l}\text { Discharged in good gen- } \\
\text { eral condition with } \\
\text { complete pain relief } \\
\text { and palpable foot } \\
\text { pulses. } \\
\text { Vessel patency with } \\
\text { absence of stenosis, } \\
\text { pseudoaneurysm or } \\
\text { recurrent aneurysm at } \\
69 \text { months. }\end{array}$ & $\begin{array}{l}\text { Presentation: Pulsatile and painful } \\
\text { mass in the right calf } \\
\text { Aetiology/risk factors: Hypertension, } \\
\text { dyslipidaemia } \\
\text { Investigations: DUS, selective } \\
\text { arteriography } \\
\text { Diagnosis: Giant tibioperoneal trunk } \\
\text { aneurysm }\end{array}$ \\
\hline $\begin{array}{l}\text { Faccenna, } \\
2011^{14}\end{array}$ & $67 \mathrm{M}$ & $\begin{array}{l}\text { Saphenous vein } \\
\text { bypass }\end{array}$ & $\begin{array}{l}\text { Discharge on day } 8 . \\
\text { Relief of symptoms. } \\
\text { Posterior tibial pulse } \\
\text { present. } \\
\text { Bypass patent at } \\
3 \text { months. }\end{array}$ & $\begin{array}{l}\text { Presentation: Pulsatile and painful } \\
\text { mass in the anterolateral compartment } \\
\text { of the right leg and blue toe syndrome } \\
\text { Aetiology/risk factors: No history of } \\
\text { trauma, claudication and/or foot ischae- } \\
\text { mia or risk factors for atherosclerotic } \\
\text { disease } \\
\text { Investigations: DUS, arteriography } \\
\text { Diagnosis: Saccular aneurysm involving } \\
\text { the tibioperoneal trunk and the origin } \\
\text { of the peroneal and posterior tibial } \\
\text { arteries }\end{array}$ \\
\hline
\end{tabular}


peripheral pulses were present, the capillary refill was normal and routine blood tests were unremarkable. In addition, establishing a diagnosis for a peroneal artery aneurysm is not always easy since general symptoms such as claudication, pain, swelling, blue toe and ischaemic leg are neither suggestive nor typical. The main diagnostic modalities for this condition are duplex ultrasonography and/or CT or magnetic resonance imaging.

Absolute indications for interventional treatment have not been clearly defined. It has been suggested that symptomatic aneurysms, those with intraluminal thrombus and those of a large size should be repaired. ${ }^{15,16}$

The choice of treatment (surgical or endovascular) depends on variables such as the size, shape and location of the aneurysm, along with the patient's co-morbidities and general fitness for reconstructive surgery. ${ }^{17}$ Surgical repair can be accomplished with an interposition vein bypass graft. Ligation is also an option in the presence of adequate collateral circulation. ${ }^{18}$ Endovascular repair consists of coil embolisation with or without covered stent placement. These methods are good alternative treatments for high risk patients for conventional surgical repair. ${ }^{17}$ In our case, given the large size of the aneurysm with possible pressure effects on adjacent structures and the relative fitness of the patient, a surgical option was deemed appropriate.

Conservative treatment in asymptomatic patients and/or those with small aneurysms as well as elderly patients and those with a significant co-morbid burden has been suggested with continuous monitoring of the aneurysm using duplex ultrasonography. ${ }^{12,19}$ Treatment should be tailored to the patient's general condition, co-morbidities, and aneurysm site and shape.

\section{Conclusions}

True aneurysm of the peroneal artery is a rare clinical condition. Surgical repair with vein interposition graft is a viable treatment option.

\section{References}

1. Sagar J, Button M. Posterior tibial artery aneurysm: a case report with review of literature. BMC Surg 2014; 14: 37.

2. Leon LR, Benn Psalms S, Stevenson S, Mills JL. Nontraumatic aneurysms affecting crural arteries: case report and review of the literature. Vascular 2007; 15: 102-108.

3. Mitchell ME, Carpenter JP. Popliteal Artery Aneurysms. In: Ernst CB, Stanley JC.Current Therapy in Vascular Surgery. 4th edn. St Louis: Mosby; 2001.

4. Sadat U, See T, Cousins $C$ et al. Peroneal artery pseudoaneurysm - a case report and literature review. BMC Surg 2007; 7: 4.

5. Brown SL, Busuttil RW, Baker JD et al. Bacteriologic and surgical determinants of survival in patients with mycotic aneurysms. J Vasc Surg 1984; 1: 541-547.

6. Ferrero E, Ferri M, Carbonatto $P$ et al. Endovascular treatment of a symptomatic mycotic aneurysm of the peroneal artery. Ann Vasc Surg 2011; 25: 982.e11-982.e14.

7. McKee MA, Ballard JL. Mycotic aneurysms of the tibioperoneal arteries. Ann Vasc Surg 1999; 13: 188-190.

8. Albayrak R, Saglam H, Emmiler M et al. Large mycotic aneurysm of the peroneal artery. J Clin Ultrasound 2007; 35: 344-346.

9. Gandhi V, Shyam V, Unnikrishnan G et al. Ruptured mycotic aneurysm of peroneal artery. EJVES Extra 2005; 10: 21-23.

10. Elford J, Ashley S, Wells I, Roobottom C. Mycotic pseudoaneurysm of the common peroneal artery treated with direct human thrombin injection. Clin Radiol Extra 2002; 57: 34-36.

11. Cappendijk VC, Mouthaan PJ. A true aneurysm of the tibioperoneal trunk. Case report and literature review. Eur J Vasc Endovasc Surg 1999; 18: 536-537.

12. Spronk S, den Hoed PT, Veen HF. Case report: blue toe syndrome caused by a true crural aneurysm. J Vasc Nurs 2003; 21: 70-71.

13. Ferrero E, Viazzo A, Robaldo A et al. True giant aneurysm of the tibio-peroneal trunk: case report and review of the literature. Vasc Endovascular Surg 2011; 45: 372-373.

14. Faccenna F, Alunno A, Felli MM et al. Tibioperoneal true aneurysm: case report and literature review. G Chir 2011; 32: 379-383.

15. Mukherjee D. Posterior approach to the peroneal artery. J Vasc Surg 1994; 19 174-178.

16. Barbano B, Gigante A, Zaccaria A et al. True posterior tibial artery aneurysm in a young patient: surgical or endovascular treatment? BMJ Case Rep 2009; bcr04.2009.1812.

17. Zaraca F, Ponzoni A, Stringari $C$ et al. The posterior approach in the treatment of popliteal artery aneurysm: feasibility and analysis of outcome. Ann Vasc Surg 2010; 24: 863-870.

18. Murakami $\mathrm{H}$, Izawa $\mathrm{N}$, Miyahara $\mathrm{S}$ et al. A true aneurysm of posterior tibial artery. Ann Vasc Surg 2011; 25: 980.e1-980.e2.

19. Hands LJ, Collin J. Infra-inguinal aneurysms: outcome for patient and limb. Br J Surg 1991; 78: 996-998. 